\title{
Mesospheric bores at southern midlatitudes observed by ISS-IMAP/VISI: a first report of an undulating wave front
}

\author{
Yuta Hozumi $^{1}$, Akinori Saito ${ }^{2}$, Takeshi Sakanoi ${ }^{3}$, Atsushi Yamazaki ${ }^{4}$, and Keisuke Hosokawa ${ }^{1}$ \\ ${ }^{1}$ Department of Information and Communication Engineering, University of \\ Electro-Communications, Tokyo, Japan \\ ${ }^{2}$ Graduate School of Science, Kyoto University, Kyoto, Japan \\ ${ }^{3}$ Planetary Plasma and Atmospheric Research Center, Tohoku University, Sendai, Japan \\ ${ }^{4}$ Institute of Space and Astronautical Science, Japan Aerospace Exploration Agency, Sagamihara, Japan
}

Correspondence: Yuta Hozumi (hozumi@uec.ac.jp)

Received: 13 April 2018 - Discussion started: 14 May 2018

Revised: 11 September 2018 - Accepted: 2 November 2018 - Published: 19 November 2018

\begin{abstract}
Large-scale spatial structures of mesospheric bores were observed by the Visible and near-Infrared Spectral Imager (VISI) of the ISS-IMAP mission (Ionosphere, Mesosphere, upper Atmosphere and Plasmasphere mapping mission from the International Space Station) in the mesospheric $\mathrm{O}_{2}$ airglow at $762 \mathrm{~nm}$ wavelength. Two mesospheric bore events in southern midlatitudes are reported in this paper: one event at $48-54^{\circ} \mathrm{S}, 10-20^{\circ} \mathrm{E}$ on 9 July 2015 and the other event at $35-43^{\circ} \mathrm{S}, 24^{\circ} \mathrm{W}-1^{\circ} \mathrm{E}$ on 7 May 2013. For the first event, the temporal evolution of the mesospheric bore was investigated from the difference of two observations in consecutive passes. The estimated eastward speed of the bore is $100 \mathrm{~m} \mathrm{~s}^{-1}$. The number of trailing waves increased with a rate of 3.5 waves $\mathrm{h}^{-1}$. Anticlockwise rotation with a speed of $20^{\circ} \mathrm{h}^{-1}$ was also recognized. These parameters are similar to those reported by previous studies based on groundbased measurements, and the similarity supports the validity of VISI observation for mesospheric bores. For the second event, VISI captured a mesospheric bore with a large-scale and undulating wave front. The horizontal extent of the wave front was $2200 \mathrm{~km}$. The long wave front undulated with a wavelength of $1000 \mathrm{~km}$. The undulating wave front is a new feature of mesospheric bores revealed by the wide field of view of VISI. We suggest that nonuniform bore propagating speed due to inhomogeneous background ducting structure might be a cause of the undulation of the wave front. Temperature measurements from the Sounding of the Atmosphere using Broadband Emission Radiometry (SABER) onboard the Thermosphere, Ionosphere, Mesosphere, Energet-
\end{abstract}

ics and Dynamics (TIMED) satellite indicated that bores of both events were ducted in a temperature inversion layer.

\section{Introduction}

A mesospheric bore is characterized by a propagating and sharp front in the upper mesosphere. The front is often followed by undulations (undular bore) or turbulence (turbulent bore). Mesospheric bores have been observed as a sharp brightness jump or drop of airglow by ground-based imagers at various longitudes from low latitude to high latitude (e.g., Taylor et al., 1995; Smith et al., 2003, 2017; Fechine et al., 2005; Nielsen et al., 2006; Li et al., 2013; Medeiros et al., 2018).

Dewan and Picard (1998) proposed an explanation of mesospheric bores as a propagating discontinuity in a stable layer or a duct in varicose mode. In varicose mode, the upper and lower surfaces of the layer oscillate symmetrically about the mid-plane. Medeiros et al. (2005) demonstrated that most bores showed the complementary effect suggested by Dewan and Picard (1998) in airglow responses, and validated the varicose-mode oscillation. By solving conservation of mass and momentum equations, Dewan and Picard (1998) calculated the speed of a bore as follows:

$$
U=\sqrt{g^{\prime} \frac{h_{1}\left(h_{1}+h_{0}\right)}{2 h_{0}} .}
$$


Here, $h_{0}$ and $h_{1}$ are the half width of a ducting layer upward and downward of a bore, respectively; $g^{\prime}$ is the gravitational acceleration corrected for buoyancy force. The mesospheric bore model in a thermal duct has been examined and validated using simultaneous lidar and airglow imager observations (Smith et al., 2003, 2005; She et al., 2004). It has been also demonstrated with simultaneous radar observations that wind has an important role in the background condition of mesospheric bores (Fechine et al., 2009; Giongo et al., 2018). Dewan and Picard (2001) provided a possible explanation of mesospheric bores through the critical layer interaction of gravity waves with the mean flow. Seyler (2005) and Laughman et al. (2009) demonstrated, by using a numerical simulation, that a wave front of a long-wavelength gravity wave in a duct can steepen and become a bore-like sharp front. Such a formation of a mesospheric bore from large-scale gravity waves was reported by Yue et al. (2010) utilizing groundbased observations. However, the generation mechanism of mesospheric bores is still not fully understood.

Historically, the study of mesospheric bores has been conducted based on ground-based measurements. Recently, Miller et al. (2015) reported two space-borne observations of mesospheric bore events by Day/Night Band (DNB) onboard the NOAA/NASA Suomi National Polar-orbiting Partnership environmental satellite. Although there are successful observations of mesospheric bores by DNB, a lot of work is left to do on the study of mesospheric bores with space-borne imaging. First, the geographical variation of the bore characteristics is not fully understood. The number of groundbased observation sites is limited, and the locations of observation sites are restricted by land-sea distribution. There are reports of bore observations at low latitudes (e.g., Medeiros et al., 2001; Fechine et al., 2005; Medeiros et al., 2018), northern midlatitudes (e.g., Taylor et al., 1995; Smith et al., 2003, 2017; Li et al., 2013), and southern high latitudes (e.g., Nielsen et al., 2006; Li et al., 2013; Medeiros et al., 2018), but there are no reports in southern midlatitudes and northern high latitudes. Second, the large-scale horizontal structure of bores is unclear. Since ground-based imagers have often observed only a portion of a bore's wave front, the typical horizontal spatial scale of mesospheric bore seems to be larger than the imager's field of view (FOV). Previous studies based on ground-based observations have provided limited information on a bore's large-scale horizontal structure. Space-borne airglow imaging is a strong tool to study mesospheric bores with global observational coverage and a wider FOV, and can overcome the limitations of ground-based observations.

The Visible and near-Infrared Spectral Imager (VISI) of the ISS-IMAP mission (Ionosphere, Mesosphere, upper Atmosphere and Plasmasphere mapping mission from the International Space Station) is another instrument that has a capability of imaging mesospheric airglow from space with a wide FOV. While Miller et al. (2015) limited their focus to illustrating the DNB's potential for bore observation, we report two successful bore events from VISI with further detailed analyses to address two topics: the latitudinal difference of the bore characteristics and the large horizontal structure. In this paper, we report two mesospheric bores observed by VISI at southern midlatitudes. The bore of event no. 1 was captured in two consecutive passes by VISI; thus, the temporal evolution of the structure can be investigated from the difference of two images. The bore showed counterclockwise rotation, while previous studies report clockwise rotation of bore fronts at northern midlatitudes (Smith et al., 2003; Li et al., 2013). As event no. 2, we report a mesospheric bore with a very long wave front exceeding $2200 \mathrm{~km}$. With the benefit of VISI's wide FOV, a new feature of the horizontally undulating wave front was captured. The vertical undulations following bore fronts have often been discussed since Dewan and Picard (1998) explained the subsequent undulation with vertical displacement in varicose mode. However, the horizontal undulation of mesospheric bore fronts has never been reported as far as we know. This paper is the first report of an undulating bore front.

\section{Instrumentation and methodology}

VISI is a visible and near-infrared spectral imager that was installed on the ISS, and made observations from September 2012 to August 2015. VISI has a grism as a disperser, and the spectral resolution $(\lambda / \Delta \lambda)$ is $\sim 800$. The detector is a backilluminated, frame transfer CCD (e2V 47-20 AIMO), with $1024 \times 1024$ pixel format, $13 \times 13 \mu \mathrm{m}$ single pixel size, and 0.92 of quantum efficiency at $630 \mathrm{~nm}$. The column axis of CCD is for space, and the raw axis is for wavelength. Onchip binning is performed along the column (spatial) axis with a nominal binning size of 16 pixel. It has two slit-shaped FOVs that are perpendicular to the ISS orbit track and $45^{\circ}$ forward/backward to nadir. VISI performs continuous linescan imaging and provides seamless two-dimensional images of airglows. The nominal exposure time is $1.0 \mathrm{~s}$. Since it requires $0.9 \mathrm{~s}$ reading time, the exposure cycle is $1.9 \mathrm{~s}$. The main targets of VISI are $\mathrm{O}_{2}(0-0)$ at $762 \mathrm{~nm}, \mathrm{OH}$ Meinel at $730 \mathrm{~nm}$, and OI at $630 \mathrm{~nm}$. In the nominal operation, the peak (maximum) and background (minimum) counts in the wavelength range around the center $(762,730$ or $630 \mathrm{~nm}) \pm 6 \mathrm{~nm}$ are recorded. By subtracting the background count from the peak count, and multiplying the calibration factor, the airglow intensity is obtained. See Sakanoi et al. (2011) for more details on the instrumentation.

Data of $\mathrm{O}_{2}(0-0)$ airglow at $762 \mathrm{~nm}$ were utilized in this study. Because there is strong absorption by the ground-state $\mathrm{O}_{2}$ in the lower atmosphere, the $\mathrm{O}_{2}(0-0)$ band is not sensitive to contamination from lower altitudes, such as city lights or moon light refraction from the cloud top. The nominal altitude of the emission is $95 \mathrm{~km}$, so data were mapped to the altitude of $95 \mathrm{~km}$. Assuming an ellipsoid with the eccentricity of World Geodetic System 84 (WGS84) and an equato- 
rial axis of $\operatorname{wgs} 84 \mathrm{~A}(6378.137 \mathrm{~km})+95 \mathrm{~km}$ as the altitude plane of $95 \mathrm{~km}$, the intersection point between the ellipsoid surface and the line of sight of each pixel was calculated. Then, we mapped the airglow intensity to the intersection point, and obtained the two-dimensional airglow image. At the mapping altitude, the horizontal width of FOV is $670 \mathrm{~km}$. The spatial resolutions are $13 \mathrm{~km}$ along and $12-15 \mathrm{~km}$ across the ISS orbit track. The typical phase speed of mesospheric bores is in the range of $60-80 \mathrm{~m} \mathrm{~s}^{-1}$ (e.g., Taylor et al., 1995; Medeiros et al., 2001; Smith et al., 2003; She et al., 2004; Smith et al., 2005; Nielsen et al., 2006; Narayanan et al., 2009; Fechine et al., 2009; Bageston et al., 2011; Li et al., 2013; Giongo et al., 2018). To the best of our knowledge, the highest bore phase speeds reported in the literature are $98 \pm 8 \mathrm{~m} \mathrm{~s}^{-1}$ (Brown et al., 2004). The speed of the ISS is $7.4 \mathrm{~km} \mathrm{~s}^{-1}$, which is significantly higher than the typical phase speed of mesospheric bores. Therefore, it is reasonable to consider that VISI observes snapshots of bore-induced airglow structure.

Temperature profiles obtained by the Sounding of the Atmosphere using Broadband Emission Radiometry (SABER) instrument onboard the Thermosphere, Ionosphere, Mesosphere, Energetics and Dynamics (TIMED) satellite were employed as supporting data to assess the background thermal structure. Vertical profiles of kinetic temperature can be retrieved from SABER measurements of $\mathrm{CO}_{2} 1.5 \mu \mathrm{m}$ earth limb emission (Mertens et al., 2001). The v2.0 level 2A data downloaded from http://saber.gats-inc.com (last access: 14 November 2018) were used in this study. The square Brunt-Väisälä frequency can be derived from a temperature profile as

$N^{2}=\frac{g}{T}\left(\Delta T_{z}+\frac{g}{C_{\mathrm{p}}}\right)$,

where $T$ is the temperature, $\Delta T_{z}$ is the vertical temperature gradient, and $C_{\mathrm{p}}$ is the specific heat at constant pressure. The square Brunt-Väisälä frequency at an altitude of $z$ is obtained from two continuous SABER temperature data by substituting $T=\left(T\left(z_{1}\right)+T\left(z_{2}\right)\right) / 2$ and $\Delta T_{z}=\left(T\left(z_{2}\right)-T\left(z_{2}\right)\right) /\left(z_{2}-\right.$ $z_{1}$ ) into Eq. (2) where $z=\left(z_{1}+z_{2}\right) / 2$. The height step of the SABER data around $95 \mathrm{~km}$ is $\sim 0.4 \mathrm{~km}$.

\section{Results and discussion}

\subsection{Event no. 1}

A sharp front followed by undulations was observed by VISI on 9 July 2015 over the South Atlantic Ocean. The front was captured in two consecutive passes so that the temporal evolution of the structure can be investigated from the observations. The airglow images obtained by the forward and backward FOVs of VISI are shown in Fig. 1. In the first pass, the center of the forward and backward FOVs crossed the front at
19:11:13 and 19:12:52 UT. In the second pass, they crossed it again at 20:49:13 and 20:50:52 UT, respectively.

In the first observations (Fig. 1a, d), a sharp brightness jump of airglow followed by wave structures can be seen around $10^{\circ} \mathrm{E}$ longitude with $\mathrm{S}-\mathrm{N}$ elongation of the front. The western (eastern) side of the front is bright (dark), and the boundary is fine. We can see small wave trains whose wave fronts are parallel to the front of the brightness jump on the western side. The front and wave crests identified in VISI images are indicated with blue lines in Fig. 1e, f. The morphological feature is exactly the same as bore-induced airglow structures reported by previous studies. Since the undulations are seen on the western side of the front, the mesospheric bore is expected to propagate eastward. Two crests were identified on the southern part of the western side of the front. The interval of the crests is $\sim 30 \mathrm{~km}$. Then, the wavelength of following waves is $\sim 30 \mathrm{~km}$. The $\mathrm{O}_{2}$ airglow brightness on the western side of the front is $2500-3000 \mathrm{R}$, which is $250 \%-300 \%$ brighter than that on the eastern side. Another enhancement of airglow brightness can be seen at $15-18^{\circ} \mathrm{E}$, but the boundary of this enhancement is not sharp, and we will not focus on this enhancement in this study.

In the second observations (Fig. 1b, d), the front moved eastward, and was observed at $16-25^{\circ} \mathrm{E}$. The amplitude of the brightness jump is almost the same as that in the first pass, 3000-3500 R in the western (bright) side as compared to $1300 \mathrm{R}$ in the eastern (dark) side. The airglow intensities both sides of the wave front were slightly brighter than the intensities in the previous pass. At $50^{\circ} \mathrm{S}$, the front moved $620 \mathrm{~km}$ eastward in the interval. Thus, if we assume a pure eastward propagation, the bore speed is estimated as $100 \mathrm{~m} \mathrm{~s}^{-1}$. This value is close to the bore speeds reported by previous studies that are typically $60-80 \mathrm{~m} \mathrm{~s}^{-1}$. The undulations were identified on the southern part in the second pass as well as in the first pass. As shown in the Fig. 1e, f, the number of wave crests increased to seven in the second pass from two in the first pass. It means that the wave adding rate is expected to be 3.5 waves $\mathrm{h}^{-1}$. This value is also similar to the wave adding rates reported previously that ranged from 1.3 to 8.6 waves $^{-1}$ (Taylor et al., 1995; Smith et al., 2003; She et al., 2004; Nielsen et al., 2006; Narayanan et al., 2009; Li et al., 2013; Smith et al., 2017).

Mesospheric bores are thought to require a channel or region of increased stability in which a bore propagates (Dewan and Picard, 1998). A mesospheric inversion layer, a large wind shear, or the combination of both can make such a structure. To assess the background condition of this bore event, both temperature and wind data are ideally needed. For the current case, however, wind data from radar or lidar are not available. Thus, we examine only background temperature structure with TIMED/SABER data. TIMED/SABER made a near-coincident observation (orbit 73617, event 82) $2.3 \mathrm{~h}$ after the second observation of VISI, at 23:10 UT on 9 July 2015 , at $52.1^{\circ} \mathrm{S}, 24.8^{\circ} \mathrm{E}$ for $95 \mathrm{~km}$ altitude (Fig. 2a). Figure $2 \mathrm{~b}$ presents the vertical temperature profile showing 

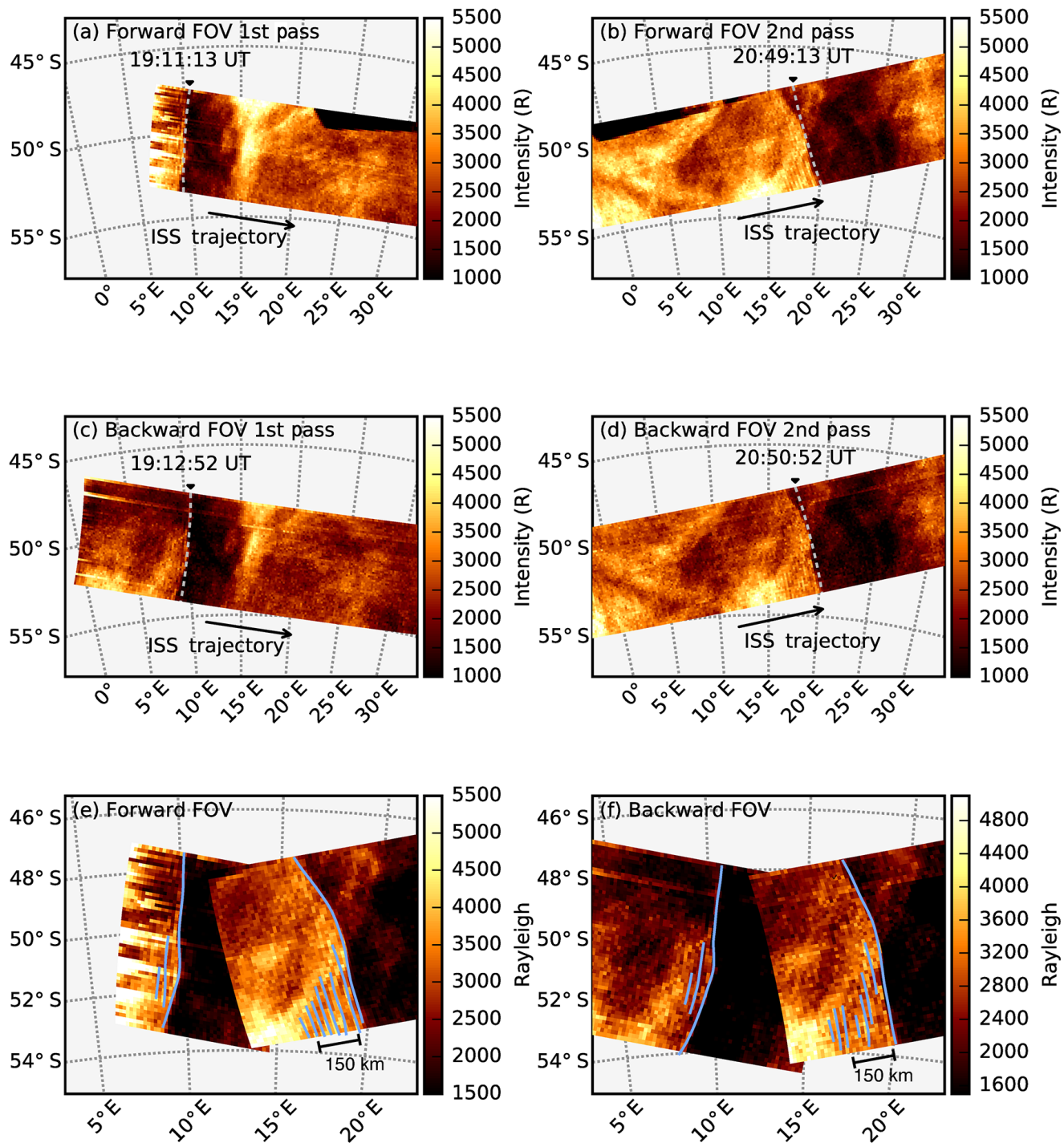

Figure 1. $\mathrm{O}_{2}(762 \mathrm{~nm})$ airglow images obtained by VISI with the forward and backward FOVs in two consecutive passes on 9 July 2015. Airglow images were mapped to the altitude of $95 \mathrm{~km}$. Panels (a) and (b) show the mesospheric bore observed by the forward FOV in the first pass and second pass, respectively. The FOV crossed the front at 19:11:13 and 20:49:13 UT. Panels (c) and (d) show the mesospheric bore observed by the backward FOV in the first pass and second pass, respectively. The FOV crossed the front at 19:12:52 and 20:50:52 UT. Panels (e) and (f) show the airglow images obtained in the two passes are shown in one plot. The airglow data are the same as the above four plots, but the images are zoomed in to show detailed wave characteristics. Blue lines indicate the bore front and the wave crests.

a $30 \mathrm{~K}$ temperature inversion at $95-100 \mathrm{~km}$ altitude, and a $10 \mathrm{~K}$ temperature inversion at $91-93 \mathrm{~km}$. The vertical profile of Brunt-Väisälä frequency derived from SABER temperature measurement is presented in Fig. 2c. A stable layer, the region of strong stability (high $N^{2}$ ) surrounded by lowstability or unstable regions (low or negative $N^{2}$ ), is recognized at $95-100 \mathrm{~km}$ altitude. This is a favorable structure for mesospheric bores in which a bore propagates in varicose mode. An unstable region around $95 \mathrm{~km}$ appears narrow, while an unstable region at $90-91 \mathrm{~km}$ is relatively thick. Then, the lower limit of the stable region might be $91 \mathrm{~km}$. In any case, TIMED/SABER data show the existence of a stable layer near the typical emission peak altitude $(95 \mathrm{~km})$ of $762 \mathrm{~nm} \mathrm{O} \mathrm{O}_{2}$ emission. Since temperature inversions are thought to be long-lived phenomena (Meriwether and Gardner, 2000; Meriwether and Gerrard, 2004), the stable layer due to the inversion layer observed by SABER is expected to exist during the VISI observation, $2.3 \mathrm{~h}$ before the SABER observation. The mesospheric bore is likely to propagate in the stable layer created by a temperature inversion.

The orientation of the wave front was a NNW-SSE direction in the second pass, while it was almost a N-S direction in the first pass. The azimuthal angle of the wave front was observed to rotate counterclockwise from $12^{\circ}$ (angle from 

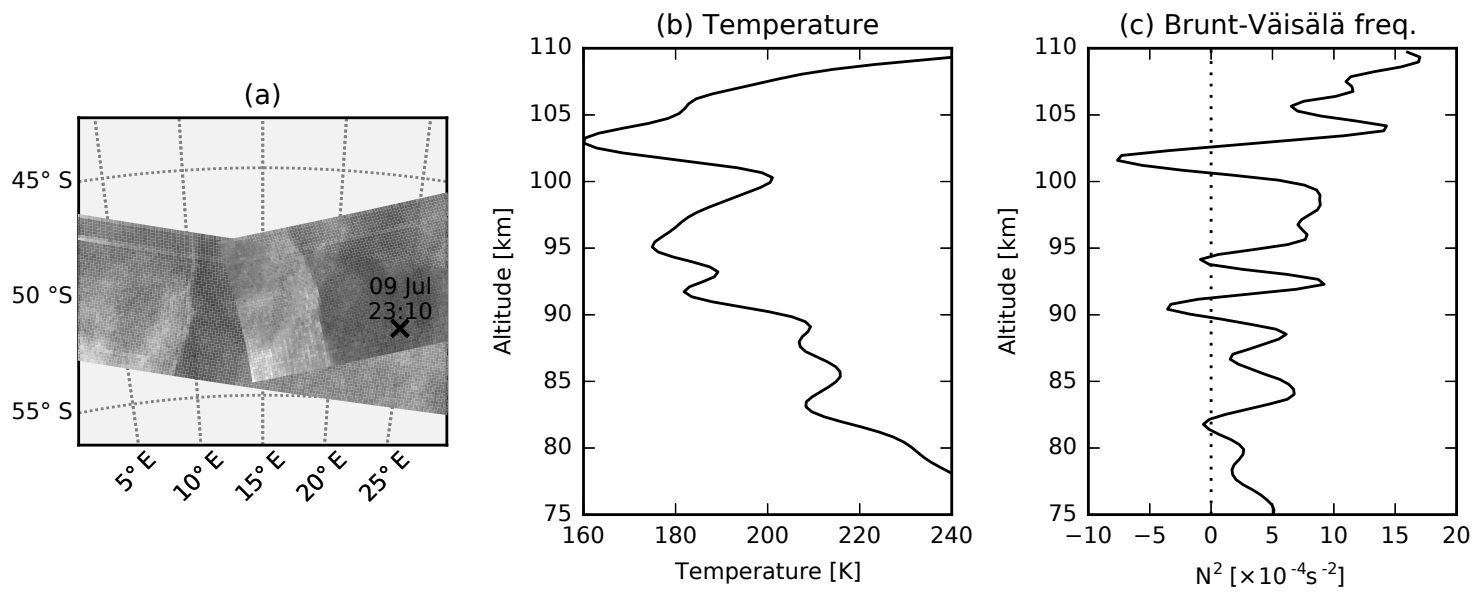

Figure 2. SABER measurements obtained $2.3 \mathrm{~h}$ after the bore event no. 1. (a) The measurement point at $95 \mathrm{~km}$ altitude is indicated by the black cross. (b) The altitude profile of temperature showing a $30 \mathrm{~K}$ temperature inversion at $95-100 \mathrm{~km}$ altitude. (c) The altitude profile of the resulting Brunt-Väisälä frequency showing a stable layer at $95-100 \mathrm{~km}$.

north to east) to $-18^{\circ}$ within one orbital period of the ISS. Thus, the rotation speed is $-20^{\circ} \mathrm{h}^{-1}$. The difference of the phase speed of the front in the southern side and northern side might be a cause of the rotation. According to Eq. (1), the propagating speed of the bore depends on the depth of the ducting layer $(U \propto \sqrt{\text { duct depth }})$ and surrounding temperature structure $\left(\right.$ via $\left.g^{\prime}\right)$. If the layer depth is thicker on the southern side, the phase speed is larger there; then, the front rotates counter clockwise.

The background wind is another important factor when we consider the rotation of the front. Generally, wind in the mesopause region is largely dominated by atmospheric tides and inertia gravity waves, and the majority of those are thought to propagate from lower atmosphere (e.g., Aso and Vincent, 1982; Nakamura et al., 1993). In winter midlatitudes, the semi-diurnal and diurnal tides have significant amplitude (Aso and Vincent, 1982). Upward propagating tides and waves have clockwise variations in the Northern Hemisphere and counterclockwise variations in the Southern Hemisphere due to the Coriolis acceleration. While the current bore in the southern midlatitude showed counterclockwise rotation, northern midlatitude bores reported in previous studies showed clockwise rotation. Smith et al. (2003) reported $6^{\circ} \mathrm{h}^{-1}$ clockwise rotation of a bore front over North America. Li et al. (2013) reported $8^{\circ} \mathrm{h}^{-1}$ clockwise rotation over northern China.

Rotation directions of these bores in both the Northern and Southern Hemisphere are consistent with the expected background wind variations that were dominated by upward propagating tides and waves. The rotation of wave fronts might be caused by background wind variations. In the past studies, to the best of our knowledge, there was no report of mesospheric bores at southern midlatitudes, where the groundbased observation sites are not dense. VISI can provide the

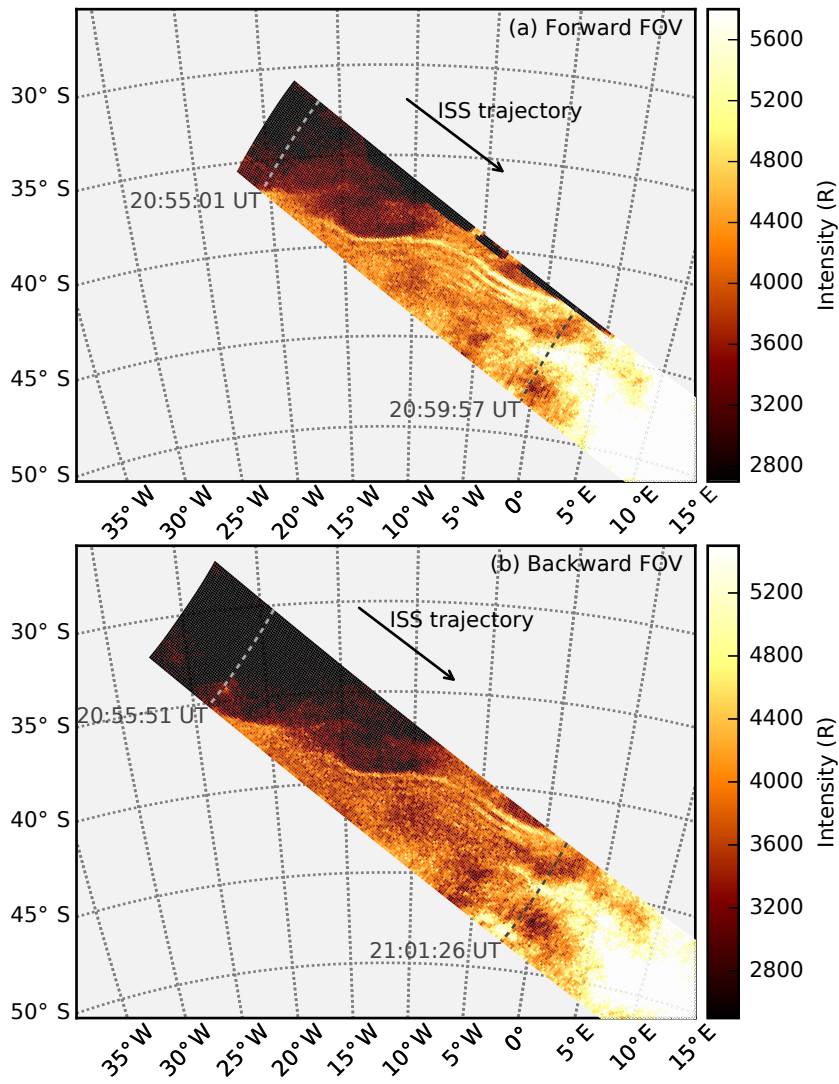

Figure 3. $\mathrm{O}_{2}(762 \mathrm{~nm})$ airglow images obtained by VISI with the forward and backward FOV on 7 May 2013. The start and end times of capturing the bore front are indicated with dashed lines. 

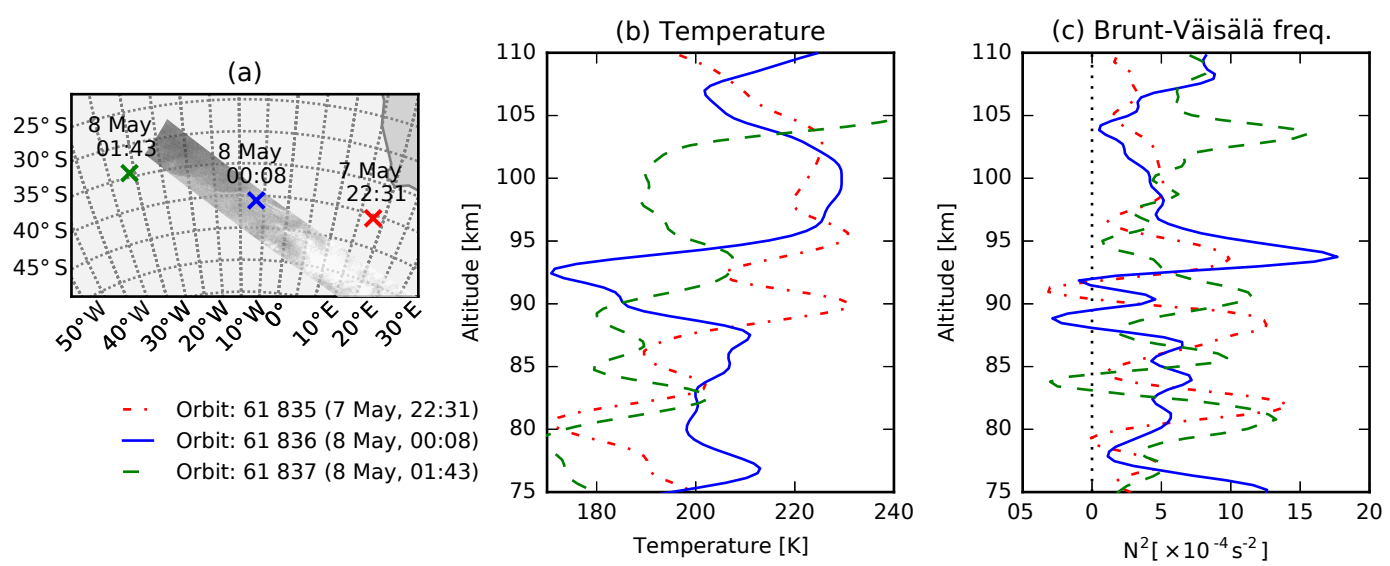

Figure 4. SABER measurements obtained from 7 May at 22:31 UT to 8 May at 01:43 UT. (a) The measurement points at $95 \mathrm{~km}$ are indicated by crosses. (b) The altitude profiles of temperature. (c) The altitude profiles of Brunt-Väisälä frequency.

southern midlatitude data and show the hemispheric difference clearly.

The bore parameters, such as phase speed, wavelength of trailing waves, and wave adding rate, were similar to those reported by previous studies based on ground-based measurements. These similarities support the validity of VISI observation for mesospheric bores. Next, we will report on the large-scale spatial structure of a mesospheric bore revealed by the wide FOV of VISI.

\subsection{Event no. 2}

A mesospheric bore with a very long wave front was observed on 7 May 2013 over the South Atlantic Ocean (35$43^{\circ} \mathrm{S}, 24^{\circ} \mathrm{W}-1^{\circ} \mathrm{E}$ ) as shown in Fig. 3. A front, characterized by a sharp increase in brightness, elongated $\mathrm{W}$ to $\mathrm{NW}$ and $\mathrm{E}$ to SE was captured from 20:55:01 to 20:59:57 UT with the forward FOV, and from 20:55:51 to 21:01:26 UT with the backward FOV. The $\mathrm{O}_{2}$ airglow brightness on the SSW side of the front is $4200-5000 \mathrm{R}$, that is $130 \%-160 \%$ brighter than that on the NNE side. Within the VISI's FOV, the wave front has a large horizontal extent exceeding $2200 \mathrm{~km}$. The small wavy structures parallel to the wave front are seen at $8-0^{\circ} \mathrm{W}$ on the SSW (bright) side of the wave front; thus, the bright front is expected to propagate NNE-ward. The wavelength of trailing waves is $50 \mathrm{~km}$. An interesting feature of this event is the undulating wave front. The wave front of the bright jump was not straight. It undulated with a wavelength of $\sim 1000 \mathrm{~km}$. The crests of the modulation are at $18^{\circ} \mathrm{W}$, $27^{\circ} \mathrm{S}$ and $6^{\circ} \mathrm{W}, 40^{\circ} \mathrm{S}$, where the front advanced forward to the propagating direction (NNE) compared to other portions of the front.

The same as event no. 1, there are no available wind data for this event. We only examine background temperature structure with TIMED/SABER data. Figure 4 shows the result of SABER measurement $1.5-4.5 \mathrm{~h}$ after the VISI obser- vation. Since the horizontal extent of the bore front is zonally long, temperature data from three passes are presented.

The nearest measurement to the bore front was made at $25^{\circ} \mathrm{E}, 40^{\circ} \mathrm{S}$ for $95 \mathrm{~km}$ altitude at 23:10 UT on 7 May 2013 (orbit 61836 , event 57 , blue line). In the temperature profile, a large $60 \mathrm{~K}$ temperature inversion layer is recognized at 93$100 \mathrm{~km}$ altitude. Figure 2c indicates the existence of a corresponding stable layer at $93-97 \mathrm{~km}$ favorable for mesospheric bore propagation. In the temperature profile of the previous pass (orbit 61835, event 58, red line), a temperature inversion can be seen at a similar altitude $(93-95 \mathrm{~km})$, but the intensity of inversion is much smaller. It is less than $30 \mathrm{~K}$. The temperature profile of the following pass (orbit 61837, event 55, green line) shows temperature inversions at $89-93 \mathrm{~km}$ and $100-105 \mathrm{~km}$; they are a little lower and higher than the previous two passes. Since three temperature profiles show the existence of a temperature inversion layer near the emission height, the mesospheric bore of event no. 2 seems to have propagated in the stable layer created by temperature inversion, the same as event no. 1 .

In this event, VISI captured the very large spatial extent of a mesospheric bore exceeding $2200 \mathrm{~km}$ long. The result indicates that the propagating region due to a mesospheric inversion layer has a similar or larger spatial extent. Although the three SABER temperature profiles obtained with a $1000 \mathrm{~km}$ interval in the horizontal and a $1.5 \mathrm{~h}$ time interval show small discrepancies in the inversion amplitude and layer altitude, the stable layer caused by the inversion layer is expected to have one continuous large horizontal extension at the time when the bore propagated. Smith et al. (2003) reported a mesospheric bore propagating over $1000 \mathrm{~km}$ and a concurrent measurement of an inversion layer at a separate observation site, and showed that inversion layers with horizontalscale sizes of $1000-1500 \mathrm{~km}$ can exist. Suzuki et al. (2013) demonstrated that a ducting gravity wave can propagate over $1800 \mathrm{~km}$ at mesopause height by using a network of ground- 
(a)

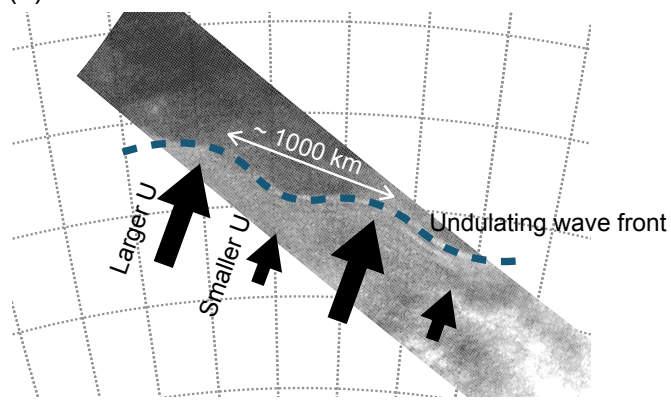

(b)

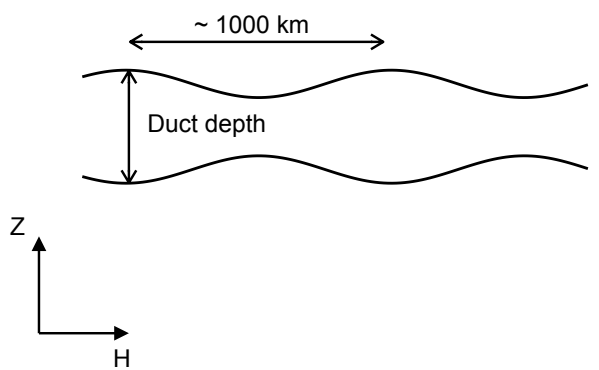

Figure 5. (a) Possible interpretation of the undulating wave front. (b) Schematic picture of a proposed modulating duct structure.

based imagers. These previous studies showed the horizontal extents of a propagating or ducting medium along the propagating direction of waves. Our result shows that the horizontal extents can also be large perpendicular to the propagating direction as it exceeds $2200 \mathrm{~km}$.

While a curved or bent wave front of a mesospheric bore has been reported (Brown et al., 2004; Smith et al., 2017), to the best of our knowledge, an undulating wave front of a mesospheric bore has never been reported. The undulating wave front seen in Fig. 3 is a new feature of mesospheric bores that was revealed by the wide FOV of space-borne imaging. A possible explanation of the undulated wave front is nonuniform bore speed along the wave front. As illustrated in Fig. 5a, periodically modulating propagating speed can cause an undulating wave front. As mentioned above, the propagating speed of bore front depends on the depth of the ducting layer and surrounding temperature structure. A spatial inhomogeneity in the ducting structure, such as duct depth or thermal structure, can cause an inhomogeneity of bore speed in space. Figure 5b shows a schematic picture of the possible modulating duct structure. Since bore speed is proportional to the square root of duct depth, a larger bore speed is expected where the duct depth is large, and a smaller bore speed is expected where the duct depth is small. Thus, if there is a modulating duct as shown in Fig. 5b, it can yield nonuniform bore speed and a resultant modulating wave front. The bore front modulation in Fig. 3 shows a sinusoidal shape. It implies that the spatial inhomogeneity in the duct depth or temperature gradient also has sinusoidal modulation. This fact suggests that the modulation in the duct depth or temperature gradient might be a result of the interaction between the stable layer and a wave with horizontal wavelength of $1000 \mathrm{~km}$.

A point-like tropospheric source location of an atmospheric gravity wave can be found by estimating the curvature of the observed wave front from airglow imagery with the assumption that the disturbance propagates radially from its source (Suzuki et al., 2007). An implication from the discussion of the undulated wave front is that such a method for source identification using the curvature of the wave front would be misleading in the case that the bore speed is nonuniform.

\section{Summary}

Two mesospheric bore events at southern midlatitudes observed by VISI were reported. For event no. 1, the temporal evolution of the bore was estimated from two consecutive VISI observations. Estimated bore parameters, such as phase speed, wavelength of trailing waves, and wave adding rate, were consistent with previous studies. These results validate the use of VISI for bore studies. This event provided information on the temporal evolution of the azimuth angle of the bore front in the southern midlatitudes. The bore was rotated counterclockwise with a speed of $20^{\circ} \mathrm{h}^{-1}$, while past studies reported clockwise rotating bores in the northern midlatitudes. The rotating directions are consistent with upward propagating tides and gravity waves, suggesting that the bore was affected by tidal backward wind variation. From event no. 2, with the benefit of the wide FOV of VISI, we found that (1) a wave front of a mesospheric bore can be long as it exceeds $2200 \mathrm{~km}$, and (2) a wave front of a mesospheric bore is not always straight or simply curved in a large-scale view; it can periodically undulate. The undulating wave front of the bore suggests that the bore speed in the duct is not uniform in space. The space-borne imaging has a wide FOV and global observation coverage, and it can be utilized to study mesospheric bores at the synoptic scale. As a future work, we plan to conduct a statistical study on the global characteristics of mesospheric bores with VISI data.

Data availability. ISS-IMAP/VISI data are available via e-mail inquiry to Akinori Saito at Kyoto University (saitoua@kugi.kyotou.ac.jp). TIMED/SABER v2.0 level 2A data were downloaded from SABER (Sounding of the Atmosphere using Broadband Emission Radiometry) Data Services by the SABER team (SABER, 2018). 
Author contributions. YH conducted the data analysis and wrote the first draft of the manuscript. AS conducted the ISS-IMAP mission. All authors contributed toward revising and improving the manuscript. All authors read and approved the final paper.

Competing interests. The authors declare that they have no conflict of interest.

Special issue statement. This article is part of the special issue "Layered phenomena in the mesopause region (ACP/AMT interjournal SI)". It is not associated with a conference.

Acknowledgements. Data utilized in this study are from the Ionosphere, Mesosphere, upper Atmosphere, and Plasmasphere mapping mission from the ISS (ISS-IMAP mission). We thank all the members of the ISS-IMAP mission. We also acknowledge the SABER team for the SABER temperature data. We thank three anonymous referees for their comments on the open discussion.

Edited by: William Ward

Reviewed by: Jose Valentin Bageston and two anonymous referees

\section{References}

Aso, T. and Vincent, R. A.: Some direct comparisons of mesospheric winds observed at Kyoto and Adelaide, J. Atmos. Terr. Phys., 44, 267-280, https://doi.org/10.1016/00219169(82)90032-0, 1982.

Bageston, J. V., Wrasse, C. M., Hibbins, R. E., Batista, P. P., Gobbi, D., Takahashi, H., Andrioli, V. F., Fechine, J., and Denardini, C. M.: Case study of a mesospheric wall event over Ferraz station, Antarctica ( $\left.62^{\circ} \mathrm{S}\right)$, Ann. Geophys., 29, 209-219, https://doi.org/10.5194/angeo-29-209-2011, 2011.

Brown, L. B., Gerrard, A. J., Meriwether, J. W., and Makela, J. J.: All-sky imaging observations of mesospheric fronts in OI $557.7 \mathrm{~nm}$ and broadband $\mathrm{OH}$ airglow emissions: Analysis of frontal structure, atmospheric background conditions, and potential sourcing mechanisms, J. Geophys. Res.-Atmos., 109, 1-19, https://doi.org/10.1029/2003JD004223, 2004.

Dewan, E. M. and Picard, R. H.: Mesospheric bores, J. Geophys. Res., 103, 6295, https://doi.org/10.1029/97JD02498, 1998.

Dewan, E. M. and Picard, R. H.: On the origin of mesospheric bores, J. Geophys. Res., 106, 2921, https://doi.org/10.1029/2000JD900697, 2001.

Fechine, J., Medeiros, A. F., Buriti, R. A., Takahashi, H., and Gobbi, D.: Mesospheric bore events in the equatorial middle atmosphere, J. Atmos. Sol.-Terr. Phy., 67, 1774-1778, https://doi.org/10.1016/j.jastp.2005.04.006, 2005.

Fechine, J., Wrasse, C. M., Takahashi, H., Medeiros, A. F., Batista, P. P., Clemesha, B. R., Lima, L. M., Fritts, D., Laughman, B., Taylor, M. J., Pautet, P. D., Mlynczak, M. G., and Russell, J. M.: First observation of an undular mesospheric bore in a Doppler duct, Ann. Geophys., 27, 1399-1406, https://doi.org/10.5194/angeo-27-1399-2009, 2009.
Giongo, G. A., Bageston, J. V., Batista, P. P., Wrasse, C. M., Bittencourt, G. D., Paulino, I., Paes Leme, N. M., Fritts, D. C., Janches, D., Hocking, W., and Schuch, N. J.: Mesospheric front observations by the $\mathrm{OH}$ airglow imager carried out at Ferraz Station on King George Island, Antarctic Peninsula, in 2011, Ann. Geophys., 36, 253-264, https://doi.org/10.5194/angeo-36-253-2018, 2018.

Laughman, B., Fritts, D. C., and Werne, J.: Numerical simulation of bore generation and morphology in thermal and Doppler ducts, Ann. Geophys., 27, 511-523, https://doi.org/10.5194/angeo-27511-2009, 2009.

Li, Q., Xu, J., Yue, J., Liu, X., Yuan, W., Ning, B., Guan, S., and Younger, J. P.: Investigation of a mesospheric bore event over northern China, Ann. Geophys., 31, 409-418, https://doi.org/10.5194/angeo-31-409-2013, 2013.

Medeiros, A. F., Taylor, M. J., Takahashi, H., Batista, P. P., and Gobbi, D.: An unusual airglow wave event observed at cachoeira paulista $23^{\circ} \mathrm{S}$, Adv. Space Res., 27, 1749-1754, https://doi.org/10.1016/S0273-1177(01)00317-9, 2001.

Medeiros, A. F., Fechine, J., Buriti, R. A., Takahashi, H., Wrasse, C. M., and Gobbi, D.: Response of $\mathrm{OH}, \mathrm{O}_{2}$ and OI5577 airglow emissions to the mesospheric bore in the equatorial region of Brazil, Adv. Space Res., 35, 1971-1975, https://doi.org/10.1016/j.asr.2005.03.075, 2005.

Medeiros, A. F., Paulino, I., Wrasse, C. M., Fechine, J., Takahashi, H., Bageston, J. V., Paulino, A. R., and Buriti, R. A.: Case study of mesospheric front dissipation observed over the northeast of Brazil, Ann. Geophys., 36, 311-319, https://doi.org/10.5194/angeo-36-311-2018, 2018.

Meriwether, J. W. and Gardner, C. S.: A review of the mesosphere inversion layer phenomenon, J. Geophys. Res.-Atmos., 105, 12405-12416, https://doi.org/10.1029/2000JD900163, 2000.

Meriwether, J. W. and Gerrard, A. J.: Mesosphere inversion layers and stratosphere temperature enhancements, Rev. Geophys., 42, 1-31, https://doi.org/10.1029/2003RG000133, 2004.

Mertens, C. J., Mlynczak, M. G., López-Puertas, M., Wintersteiner, P. P., Picard, R. H., Winick, J. R., Gordley, L. L., and Russell, J. M.: Retrieval of mesospheric and lower thermospheric kinetic temperature from measurements of $\mathrm{CO}_{2} 15 \mathrm{vm}$ earth limb emission under non-LTE conditions, Geophys. Res. Lett., 28, 13911394, https://doi.org/10.1029/2000GL012189, 2001.

Miller, S. D., Straka, W. C., Yue, J., Smith, S. M., Alexander, M. J., Hoffmann, L., Setvák, M., and Partain, P. T.: Upper atmospheric gravity wave details revealed in nightglow satellite imagery, P. Natl. Acad. Sci., 112, E6728-E6735, https://doi.org/10.1073/pnas.1508084112, 2015.

Nakamura, T., Tsuda, T., Yamamoto, M., Fukao, S., and Kato, S.: Characteristics of gravity waves in the mesosphere observed with the middle and upper atmosphere radar. I: Momentum flux, J. Geophys. Res., 98, 8899-8910, 1993.

Narayanan, V. L., Gurubaran, S., and Emperumal, K.: A case study of a mesospheric bore event observed with an all-sky airglow imager at Tirunelveli $\left(8.7^{\circ} \mathrm{N}\right)$, J. Geophys. Res.-Atmos., 114, 19, https://doi.org/10.1029/2008JD010602, 2009.

Nielsen, K., Taylor, M. J., Stockwell, R. G., and Jarvis, M. J.: An unusual mesospheric bore event observed at high latitudes over Antarctica, Geophys. Res. Lett., 33, 10-13, https://doi.org/10.1029/2005GL025649, 2006. 
Sakanoi, T., Akiya, Y., Yamazaki, A., Otsuka, Y., Saito, A., and Yoshikawa, I.: Imaging Observation of the Earth's Mesosphere, Thermosphere and Ionosphere by VISI of ISSIMAP on the International Space Station, IEEJ Transactions on Fundamentals and Materials, 131, 983-988, https://doi.org/10.1541/ieejfms.131.983, 2011.

Seyler, C. E.: Internal waves and undular bores in mesospheric inversion layers, J. Geophys. Res., 110, D09S05, https://doi.org/10.1029/2004JD004685, 2005.

She, C. Y., Li, T., Williams, B. P., Yuan, T., and Picard, R. H.: Concurrent $\mathrm{OH}$ imager and sodium temperature/wind lidar observation of a mesopause region undular bore event over Fort Collins/Platteville, Colorado, J. Geophys. Res.-Atmos., 109, 18, https://doi.org/10.1029/2004JD004742, 2004.

Smith, S. M., Taylor, M. J., Swenson, G. R., She, C. Y., Hocking, W., Baumgardner, J., and Mendillo, M.: A multidiagnostic investigation of the mesospheric bore phenomenon, J. Geophys. Res.Space, 108, 1-18, https://doi.org/10.1029/2002JA009500, 2003.

Smith, S. M., Friedman, J., Raizada, S., Tepley, C., Baumgardner, J., and Mendillo, M.: Evidence of mesospheric bore formation from a breaking gravity wave event: Simultaneous imaging and lidar measurements, J. Atmos. Sol.-Terr. Phy., 67, 345-356, https://doi.org/10.1016/j.jastp.2004.11.008, 2005.

Smith, S. M., Stober, G., Jacobi, C., Chau, J. L., Gerding, M., Mlynczak, M. G., Russell, J. M., Baumgardner, J. L., Mendillo, M., Lazzarin, M., and Umbriaco, G.: Characterization of a Double Mesospheric Bore Over Europe, J. Geophys. Res.-Space, 122, 1-13, https://doi.org/10.1002/2017JA024225, 2017.
Sounding of the Atmosphere using Broadband Emission Radiometry (SABER): TIMED/SABER v2.0 level 2A data, available at: http://saber.gats-inc.com, last access: 14 November 2018.

Suzuki, S., Shiokawa, K., Otsuka, Y., Ogawa, T., Nakamura, K., and Nakamura, T.: A concentric gravity wave structure in the mesospheric airglow images, J. Geophys. Res.-Atmos., 112, D02102, https://doi.org/10.1029/2005JD006558, 2007.

Suzuki, S., Shiokawa, K., Otsuka, Y., Kawamura, S., and Murayama, Y.: Evidence of gravity wave ducting in the mesopause region from airglow network observations, Geophys. Res. Lett., 40, 601-605, https://doi.org/10.1029/2012GL054605, 2013.

Taylor, M. J., Turnbull, D. N., and Lowe, R. P.: Spectrometric and imaging measurements of a spectacular gravity wave event observed during the ALOHA-93 Campaign, Geophys. Res. Lett., 22, 2849-2852, https://doi.org/10.1029/95GL02948, 1995.

Yue, J., She, C.-y., Nakamura, T., Harrell, S., and Yuan, T.: Mesospheric bore formation from large-scale gravity wave perturbations observed by collocated all-sky $\mathrm{OH}$ imager and sodium lidar, J. Atmos. Sol.-Terr. Phy., 72, 7-18, https://doi.org/10.1016/j.jastp.2009.10.002, 2010. 